ARTICLE

\title{
Enantioselective construction of six- and seven-membered triorgano-substituted silicon-stereogenic heterocycles
}

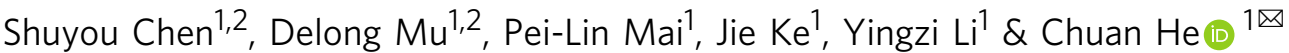

\begin{abstract}
The exploitation of chirality at silicon in asymmetric catalysis is one of the most intriguing and challenging tasks in synthetic chemistry. In particular, construction of enantioenriched mediem-sized silicon-stereogenic heterocycles is highly attractive, given the increasing demand for the synthesis of novel functional-materials-oriented silicon-bridged compounds. Here, we report a rhodium-catalyzed enantioselective construction of six- and sevenmembered triorgano-substituted silicon-stereogenic heterocycles. This process undergoes a direct dehydrogenative $\mathrm{C}-\mathrm{H}$ silylation, giving access to a wide range of triorgano-substituted silicon-stereogenic heterocycles in good to excellent yields and enantioselectivities, that significantly enlarge the chemical space of the silicon-centered chiral molecules. Further elaboration of the chiral monohydrosilane product delivers various corresponding tetraorgano-substituted silicon-stereogenic heterocycles without the loss of enantiopurity. These silicon-bridged heterocycles exhibit bright blue fluorescence, which would have potential application prospects in organic optoelectronic materials.
\end{abstract}

\footnotetext{
${ }^{1}$ Shenzhen Grubbs Institute and Department of Chemistry, Guangdong Provincial Key Laboratory of Catalysis, Southern University of Science and Technology, Shenzhen, Guangdong, China. ${ }^{2}$ These authors contributed equally: Shuyou Chen, Delong Mu. ${ }^{凶}$ email: hec@sustech.edu.cn
} 
ilicon-containing $\pi$-conjugated molecules are an emerging class of optoelectronic materials, that have been widely used as key components in organic light-emitting materials, thin-film transistors, fluorescent sensors, solar cells, electroluminescent devices, and so on ${ }^{1-8}$. Incorporation of a silylene bridge across a $\pi$ conjugated framework lowers the LUMO of the parent conjugated system via $\sigma^{*}-\pi^{*}$ conjugation, that results the unique optical and electronic properties of these silicon-containing $\pi$-conjugated molecules ${ }^{9-13}$. In light of this fact, development of new synthetic methods for the construction of these silylene-bridged compounds with broad structural variations is of great importance for advanced modification and exploitation of functional organic materials exhibiting unique properties. During the past decades, many endeavours have been made, delivering a variety of five-membered siliconbridged biaryls such as siloles, benzosiloles, 9-silafluorenes, benzosilolometallocenes, and so on (Fig. 1a $)^{6,13-30}$. Among those elegant

a Representative silicon-containing $\pi$-conjugated molecules<smiles>[R]C1=C([R])[Si](C)(C)[Si](C)(C)C1[R]</smiles><smiles>[R]C1=C([R])[Si](C)(C)c2ccccc21</smiles><smiles>[R]c1ccc2c(c1)[Si](C)(C)c1cc([R])ccc1-2</smiles><smiles></smiles>

\section{b Previous work: 6-membered tetraorgano-substituted Si-stereogenic silanes}<smiles>[R7]C#C[I-]P</smiles>

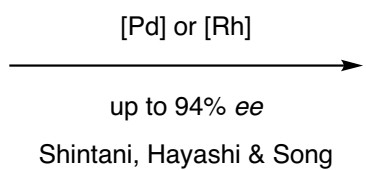<smiles>[R]C1=C([R])[Si]([R7])([R])CCC1</smiles><smiles></smiles>

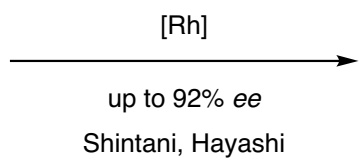

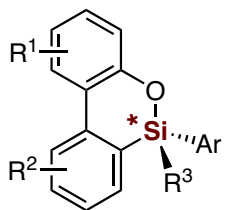<smiles>[R]c1ccc([Si]([R1])(c2ccccc2)c2c(N)cc([R])cc2[O-])cc1</smiles>

$[\mathrm{Pd}]$

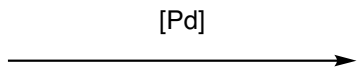

up to $98 \%$ ee

Shintani, Nozaki<smiles>[R]c1ccc2c(c1)[Si]([R1])(c1ccccc1)c1ccccc1N2</smiles>

C This work: 6- and 7-membered triorgano-substituted Si-stereogenic heterocycles<smiles>[X]c1cccc(S)c1-c1ccccc1-c1ccccc1</smiles>

$\left[\mathrm{Rh}^{\prime}\right]$ chiral diphosphine<smiles></smiles>
$X=N R, O, S$

- silicon-stereogenic heterocycles

- mild conditions, $\mathrm{H}_{2}$ as the byproduct
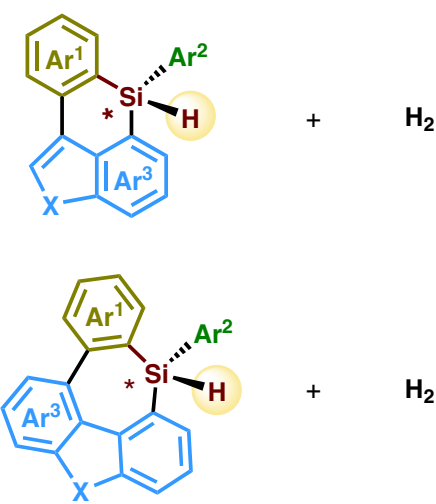

- chiral 6 and 7-membered sila-rings

- 29 examples, up to $99 \%$ ee

Fig. 1 Construction of silicon-containing $\boldsymbol{\pi}$-conjugated molecules. a Representative silicon-containing $\pi$-conjugated molecules. $\mathbf{b}$ Asymmetric synthesis of six-membered tetraorgano-substituted Si-stereogenic silanes (previous work). c Enantioselective construction of six- and seven-membered triorganosubstituted Si-stereogenic heterocycles (this work). 


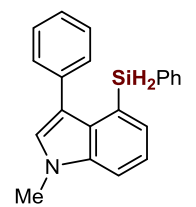

$1 \mathrm{a}$

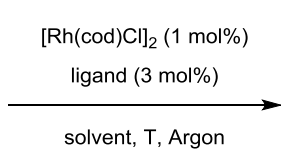

solvent, T, Argon

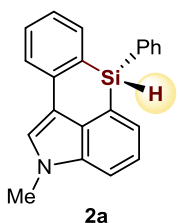

$2 a$

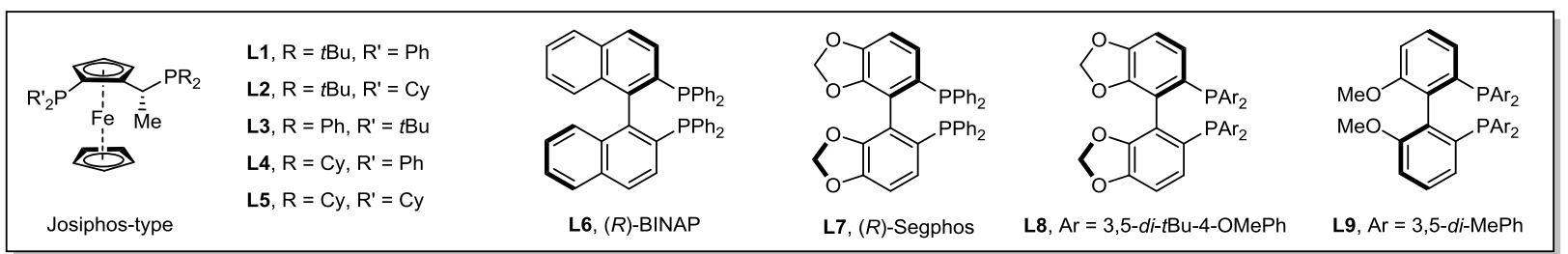

\begin{tabular}{cccccc}
\hline Entry & Ligand & Solvent & T $\left({ }^{\circ} \mathbf{C}\right)$ & Yield (\%) & $\boldsymbol{e e ~ ( \% ) ~}$ \\
\hline 1 & $\mathbf{L 1}$ & benzene & 60 & 72 & 92 \\
2 & $\mathbf{L 1}$ & toluene & 60 & 76 & 97 \\
3 & $\mathbf{L 1}$ & $p$-xylene & 60 & 66 & 82 \\
4 & $\mathbf{L 1}$ & mesitylene & 60 & 75 & 93 \\
5 & $\mathbf{L 1}$ & cyclohexane & 60 & 65 & 86 \\
6 & $\mathbf{L 1}$ & toluene & 40 & 25 & 98 \\
7 & $\mathbf{L 1}$ & toluene & 50 & 48 & 98 \\
8 & $\mathbf{L 1}$ & toluene & 70 & $87(83)$ & 94 \\
9 & $\mathbf{L 1}$ & toluene & 80 & 87 & - \\
10 & $\mathbf{L 2}$ & toluene & 70 & $<10$ & 79 \\
11 & $\mathbf{L 3}$ & toluene & 70 & 50 & 96 \\
12 & $\mathbf{L 4}$ & toluene & 70 & 88 & 79 \\
13 & $\mathbf{L 5}$ & toluene & 70 & 87 & 91 \\
14 & $\mathbf{L 6}$ & toluene & 70 & 86 & 75 \\
15 & $\mathbf{L 7}$ & toluene & 70 & 68 & 75 \\
16 & $\mathbf{L 8}$ & toluene & 70 & 86 & 88 \\
17 & $\mathbf{L 9}$ & toluene & 70 & & 79 \\
\hline
\end{tabular}

Fig. 2 Development of reaction conditions. Conditions: $\mathbf{1 a}(0.1 \mathrm{mmol}),[\mathrm{Rh}(\mathrm{cod}) \mathrm{Cl}]_{2}(1 \mathrm{~mol} \%)$, ligand $(3 \mathrm{~mol} \%)$, in $1.0 \mathrm{~mL}$ solvent under Argon atmosphere. The yield was determined by ${ }^{1} \mathrm{H}$ NMR using $\mathrm{CH}_{2} \mathrm{Br}_{2}$ as internal standard, yield in brackets is isolated yield. The ee values were determined by chiral $\mathrm{HPLC}$.

silicon-bridged biaryls, only limited examples possess six- or sevenmembered silicon-bridged $\pi$-conjugated scaffolds ${ }^{31-38}$, and even less examples display silicon-stereogenic centers. To the best of our knowledge, only Shintani, Hayashi, Nozaki et al. and Song have succeeded in forming six-membered tetraorgano-substituted siliconstereogenic silanes (Fig. 1b) ${ }^{39-43}$, while the construction of Sichirality on six- and seven-membered triorgano-substituted monohydrosilanes via asymmetric catalysis is still unknown to date, which is presumably due to a lack of general and efficient synthetic methods. Given the increasing demand for the synthesis of novel functional-materials-oriented silicon-bridged biaryls, construction of six- or seven-membered monohydrosilanes in a chiral version is highly attractive. These interesting chiral monohydrosilane heterocycles may find various synthetic applications in stereospecific transformations ${ }^{44-49}$, which could lead to their potential applications in new chiral organic materials.

Historically, enantioselective synthesis of silicon-stereogenic silanes is one of the most challenging tasks in synthetic chemistry ${ }^{47,50-53}$.
The preparation of silicon-stereogenic silanes in enantiopure or enantioenriched form is mainly restricted to the resolution with chiral auxiliary $47,50,51$. Encouragingly, in the past two decades, a number of research efforts have been dedicated to the design and development of chiral transition-metal catalysts, that can perform catalytic asymmetric transformation of prochiral dihydrosilanes or tetraorganosilanes to enantioenriched silicon-stereogenic silanes ${ }^{54-56}$. However, the limited silane substrate scope and relatively poor enantiocontrol still need to be expanded and improved. Therefore, the exploration and development of efficient catalytic methods that enable the construction of new scaffold silicon-stereogenic silanes with high enantioselectivities is highly warranted.

With the continued interest in silicon-stereogenic chemistry, we questioned whether we could utilize asymmetric dehydrogenative C-H silylation toolbox ${ }^{57,58}$ for the construction of six- or sevenmembered silicon-stereogenic silanes. To achieve this target, three major obstacles are expected: (1) the intramolecular $\mathrm{C}-\mathrm{H}$ silylation must proceed through a disfavoured seven- or eight-membered- 

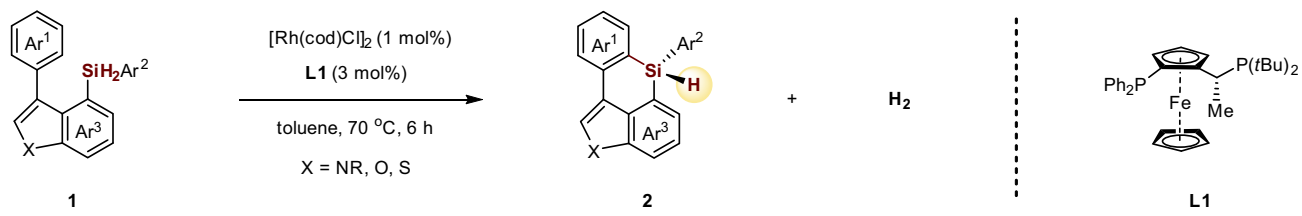

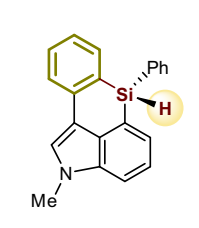

$2 a^{a}, 85 \%(1.3 \mathrm{~g}), 98 \%$ ee
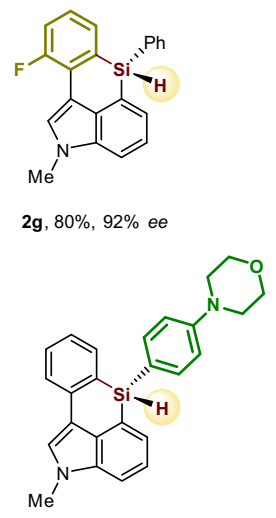

2I, $78 \%, 93 \%$ ee

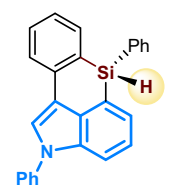

$2 r, 72 \%, 95 \%$ ee

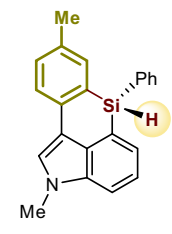

2b, $78 \%, 96 \%$ ee

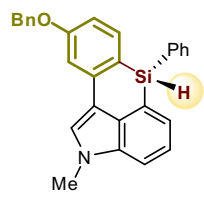

2h, $82 \%, 97 \%$ ee

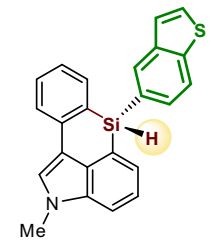

2m, $24 \%, 90 \%$ ee

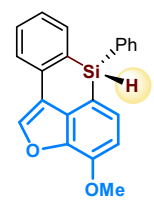

2s, $60 \%, 95 \%$ ee

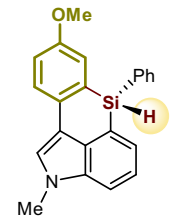

2c, $76 \%, 96 \%$ ee

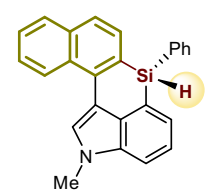

2i, $30 \%, 87 \%$ ee

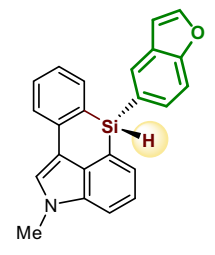

2n, $50 \%, 94 \%$ ee

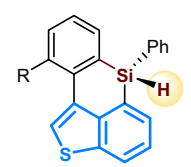

$\mathrm{R}=\mathrm{OMe}, \mathbf{2} \mathbf{t}^{\mathrm{c}}, 53 \%, 94 \%$ ee $\mathrm{R}=$ OTBS, $\mathbf{2 u}, 61 \%, 95 \%$ ee

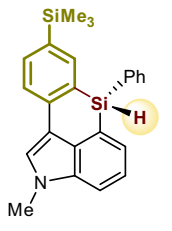

2d, $71 \%, 97 \%$ ee

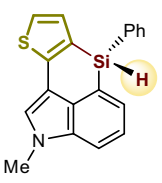

2j, $91 \%, 91 \%$ ee

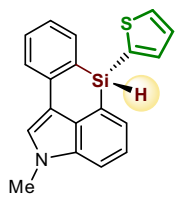

2o, $62 \%, 90 \%$ ee

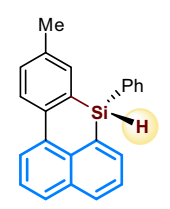

$2 \mathbf{v}^{\mathrm{d}}, \mathbf{7 6} \%, 97 \%$ ee

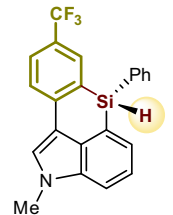

$2 e, 70 \%, 92 \%$ ee

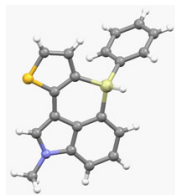

2j, X-ray structure

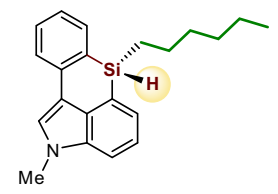

2p, $80 \%, 98 \%$ ee

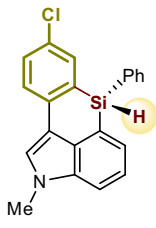

$\mathbf{2 f}^{\mathrm{b}}, \mathbf{7 4} \%, 92 \%$ ee

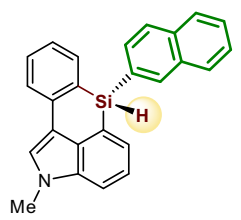

2k, $75 \%, 96 \%$ ee

Fig. 3 Scope of six-membered triorgano-substituted silicon-stereogenic heterocycles. Reaction conditions: $1(0.1 \mathrm{mmol}),[\mathrm{Rh}(\mathrm{cod}) \mathrm{Cl}]_{2}(1 \mathrm{~mol} \%), \mathbf{L 1}$ (3 mol\%) in toluene $(1 \mathrm{~mL})$ at $70{ }^{\circ} \mathrm{C}$ for $6 \mathrm{~h}$. a Reaction was performed at $5 \mathrm{mmol}$ scale. $\mathbf{b} \mathbf{~} \mathbf{5}$ was used as ligand. $\mathbf{c}[\mathrm{Rh}(\mathrm{cod}) \mathrm{Cl}]_{2}(4 \mathrm{~mol} \%), \mathbf{L 1}(8 \mathrm{~mol} \%)$ was used. d $\left[\mathrm{Rh}(\operatorname{cod}) \mathrm{Cl}_{2}(2 \mathrm{~mol} \%), \mathbf{L 1}(4 \mathrm{~mol} \%)\right.$ in toluene $(1 \mathrm{~mL})$ at $60^{\circ} \mathrm{C}$ for $8 \mathrm{~h}$. e $[\mathrm{Rh}(\mathrm{cod}) \mathrm{Cl}]_{2}(2 \mathrm{~mol} \%), \mathbf{L}(6 \mathrm{~mol} \%)$ was used. $\mathbf{f ~} \mathbf{L 7}$ was used as ligand. Xray crystallographic analysis of $\mathbf{2 j}$ allowed to determine the absolute configuration; and configurations of the products $\mathbf{2}$ were assigned by analogy.

ring cyclometallated intermediate, which would be rather challenging; (2) the competing dehydrogenative homo-coupling of dihydrosilanes is plausible $e^{59,60}$; (3) the control of high enantioselectivity is elusive. Herein, we report the exploration and realization of a rhodium-catalyzed enantioselective construction of six- and sevenmembered silicon-stereogenic silanes by dehydrogenative $\mathrm{C}-\mathrm{H}$ silylation, which give access to a variety of highly functionalized triorgano-substituted silicon-stereogenic heterocycles (Fig. 1c).

\section{Results and discussion}

Investigations of reaction conditions. We commenced our studies of the enantioselective $\mathrm{C}-\mathrm{H}$ silylation using an indole based dihydrosilane substrate 1a, which could presumably undergo $\mathrm{C}-\mathrm{H}$ silylation of the $\mathrm{C} 3$ aryl group via a seven-membered metallocycle intermediate. The reason for choosing indole skeleton in the research is because silicon-bridged biaryls consisting of arenes and indole rings were found to exhibit intense blue fluorescence and high quantum yields, which are highly attractive as key components to be used in optoelectronic devices ${ }^{61}$. To our delight, we found that treatment of $\mathbf{1 a}$ with $[\mathrm{Rh}(\operatorname{cod}) \mathrm{Cl}]_{2}(1 \mathrm{~mol} \%)$ as the catalyst and Josiphos L1 (3 mol\%) as the chiral ligand in various nonpolar solvents at $60^{\circ} \mathrm{C}$ successfully delivered the desired $\mathrm{C}-\mathrm{H}$ silylation/cyclization six-membered silicon-stereogenic products in decent yields and enantioselectivities (Fig. 2, entries 1-5). The effect of the temperature on the reaction is then investigated. The reaction at 40 or $50{ }^{\circ} \mathrm{C}$ showed excellent enantioselectivity $(98 \%$ ee), but gave a lower yield (Fig. 2, entries 6-7). Increasing the temperature to $70^{\circ} \mathrm{C}$ improved the yield to $87 \%$ with $96 \%$ eee When the reaction was carried out at $80^{\circ} \mathrm{C}$, a slightly lower enantioselectivity (94\% ee) was observed (Fig. 2, entries 8-9). Further examination of the chiral ligands showed that, besides Josiphos type ligand (L1, L3, L4, and L5), other type of diphosphine ligands such as BINAP (L6), Segphos (L7 and L8) and MeOBIPHEP (L9) were also effective for this transformation, albeit in a relatively lower ee (Fig. 2, entries 10-17). 


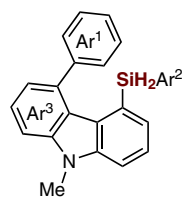

3

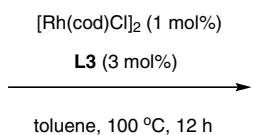

toluene, $100^{\circ} \mathrm{C}, 12 \mathrm{~h}$

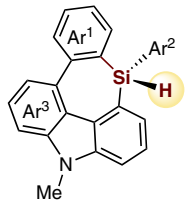

$\mathrm{H}_{2}$

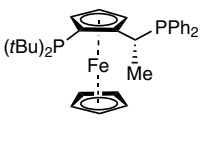

L3<smiles>COc1cc2c3c4c(cccc4n(C)c3c1-c1ccccc1)[Si](c1ccccc1)c1ccccc1-2</smiles>

4a, $78 \%, 90 \%$ ee

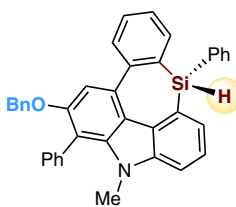

4b, $55 \%, 85 \%$ ee<smiles>Cn1c2cccc3c2c2c(cc(OC(F)(F)F)c(-c4ccccc4)c21)-c1ccccc1[SiH]3c1ccccc1</smiles>

$4 c, 68 \%, 90 \%$ ee

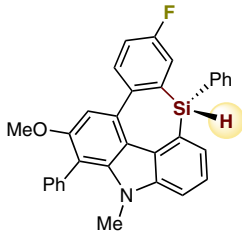

4d, $80 \%, 91 \%$ ee

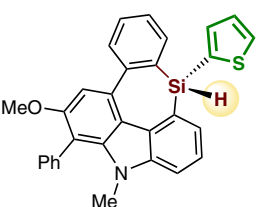

$4 e, 40 \%, 86 \%$ ee

Fig. 4 Scope of seven-membered triorgano-substituted silicon-stereogenic heterocycles. Reaction conditions: $3(0.1 \mathrm{mmol}),[\mathrm{Rh}(\mathrm{cod}) \mathrm{Cl}]_{2}(1 \mathrm{~mol} \%), \mathbf{L} 3$ (3 mol\%) in toluene $(1 \mathrm{~mL})$ at $100^{\circ} \mathrm{C}$ for $12 \mathrm{~h}$.

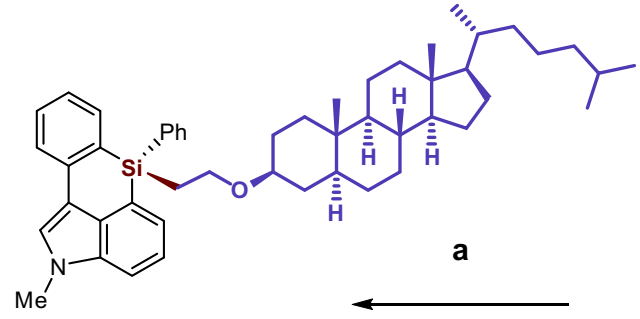

5a, $77 \%, 98 \%$ de<smiles>COc1ccc([Si]2(c3ccccc3)c3ccccc3-c3cn(C)c4cccc2c34)cc1</smiles>

5c, $72 \%, 98 \%$ ee

C

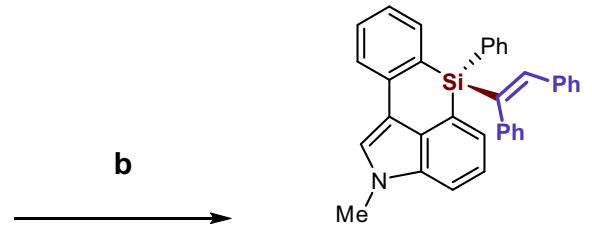

5b, $70 \%, 98 \%$ ee

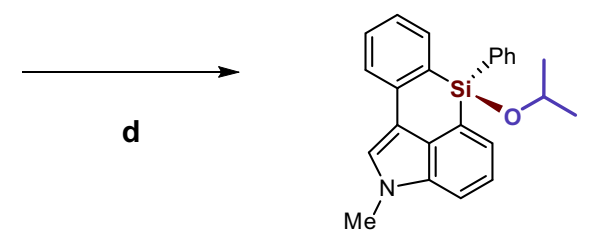

5d, $60 \%, 98 \%$ ee

d<smiles></smiles>

$4 a, 90 \%$ ee<smiles>[2H][N+]1(C)c2ccccc2-c2cccc3cccc1c23</smiles>

2a, $98 \%$ ee

$5 \mathrm{~d}, 60 \%, 98 \%$ ee

Fig. 5 Derivatization of the Si-stereogenic heterocycles. Reaction conditions: a $\left[R h(\operatorname{cod}) \mathrm{Cl}_{2}(2 \mathrm{~mol} \%)\right.$, (racemic)-Josiphos $\mathbf{L 1}$ (4 mol\%), vinyl ether (2.0 equiv), toluene, $60^{\circ} \mathrm{C}, 12 \mathrm{~h}$, de = diastereomic excess. b Pt(dvds) $\left(10 \mu \mathrm{L}, 0.1 \mathrm{M}\right.$ in xylene), 1,2-diphenylacetylene (2.0 equiv), toluene, $40{ }^{\circ} \mathrm{C}, 12 \mathrm{~h}$. c Pd $\left(t \mathrm{Bu}_{3} \mathrm{P}\right)_{2}(2 \mathrm{~mol} \%), 4$-iodoanisole (2.0 equiv), $\mathrm{K}_{3} \mathrm{PO}_{4}$ (3.0 equiv), NMP, rt, $12 \mathrm{~h} . \mathbf{d}$ [Rh(cod)Cl] 2 ( 2 mol\%), (racemic)-Josiphos L1 (4 mol\%), acetone (2.0 equiv), toluene, $60^{\circ} \mathrm{C}, 12 \mathrm{~h}$. e $\left[\mathrm{Rh}(\mathrm{cod}) \mathrm{Cl}_{2}\right.$ ( $2 \mathrm{~mol} \%$ ), (racemic)-Josiphos $\mathbf{L 1}$ ( $4 \mathrm{~mol} \%$ ), vinyl ferrocene $\left(2.0\right.$ equiv), toluene, $60{ }^{\circ} \mathrm{C}, 12 \mathrm{~h} . \mathrm{X}$-ray crystallographic analysis of $\mathbf{6 a}$ allowed to determine the absolute configuration; and configurations of the products $\mathbf{4}$ were assigned by analogy.

Substrate scope of six-membered triorgano-substituted siliconstereogenic heterocycles. With the optimized conditions in hand, we next examined the scope for this rhodium-catalyzed asymmetric dehydrogenative $\mathrm{C}-\mathrm{H}$ silylation for the construction of sixmembered triorgano-substituted silicon-stereogenic heterocycles
(Fig. 3). First, the reaction of model substrate 1a proceeded smoothly in a gram scale ( $85 \%$ yield, $1.3 \mathrm{~g}$ ) with an even better enantioselectivity (2a). The reacting aromatic rings $\left(\mathrm{Ar}^{1}\right.$, yellow part) bearing electron-donating methyl (2b), methoxy (2c), trimethylsilyl (2d), benzyloxy (2h) groups, and electron-withdrawing 
a
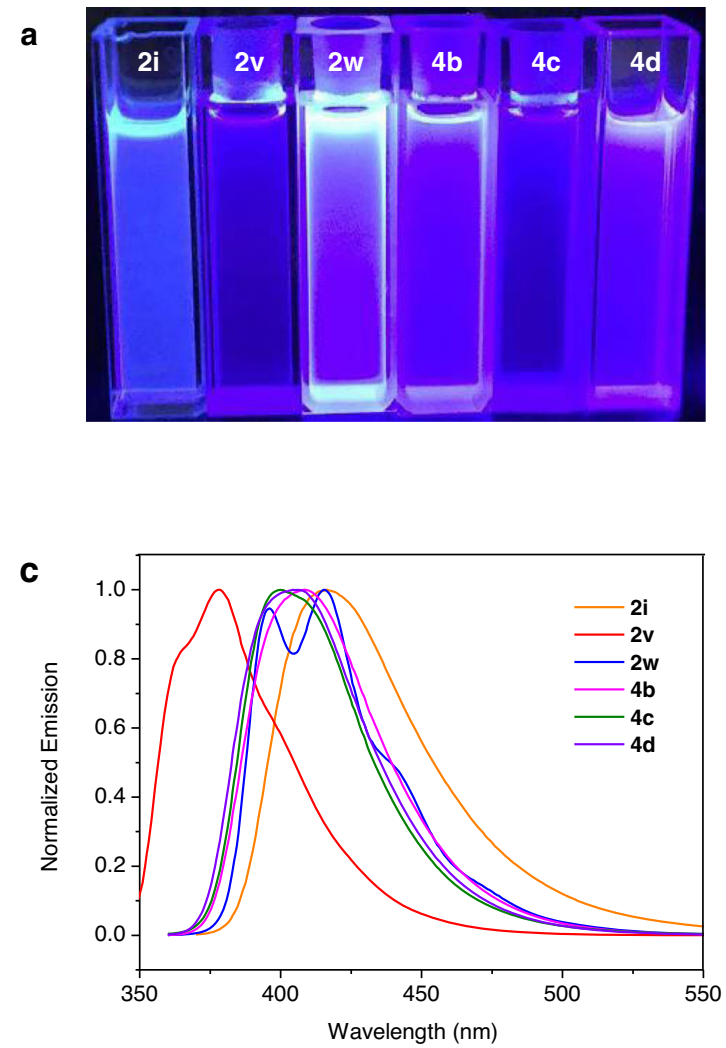

e

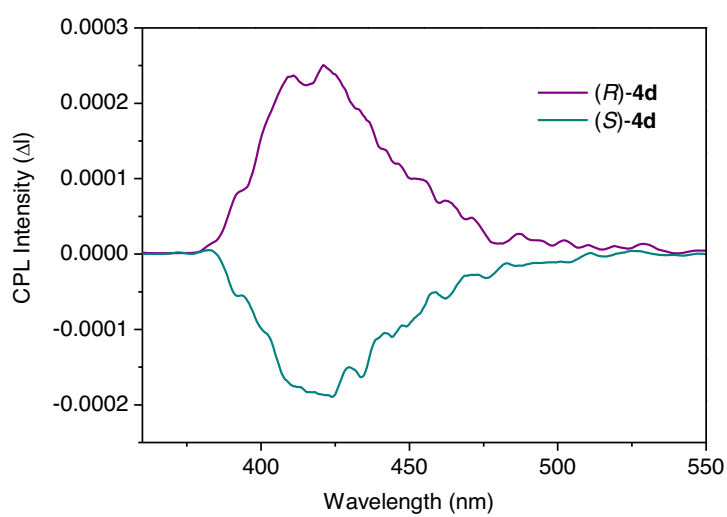

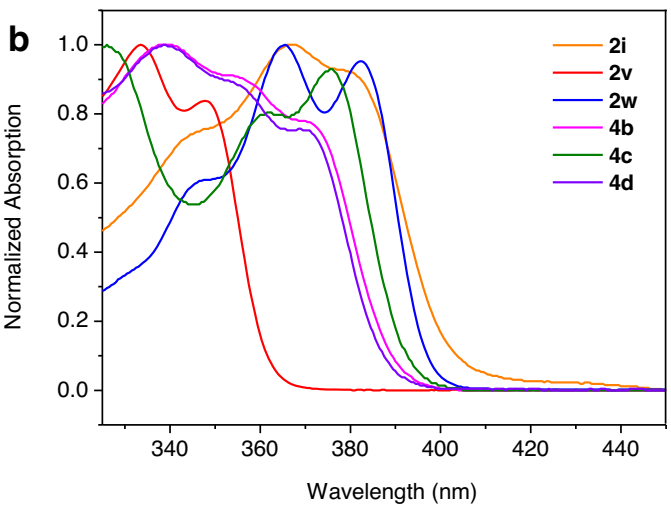

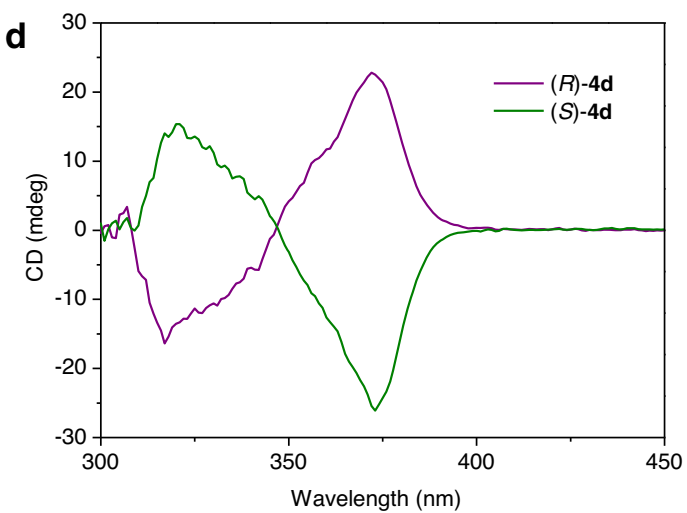

\section{f}

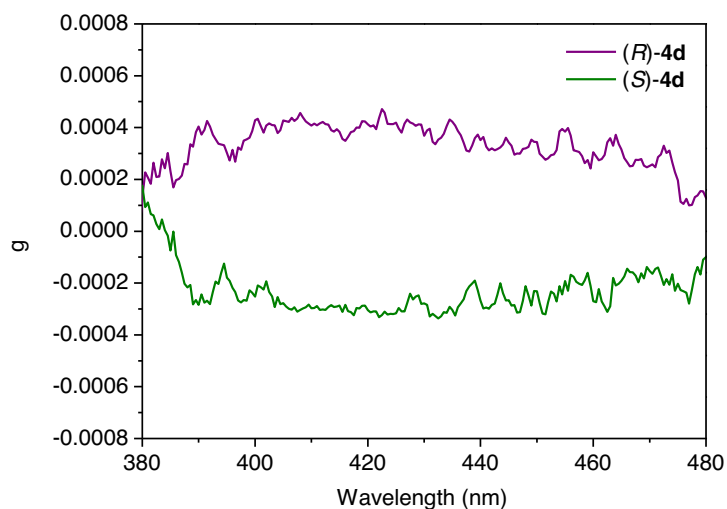

Fig. 6 Photophysical properties investigations. a Fluorescence images of selected silicon-bridged heterocycles $(\lambda e x=365 \mathrm{~nm})$. b Absorption spectra of selected silicon-bridged heterocycles in $\mathrm{CHCl}_{3}\left(10^{-5} \mathrm{M}\right)$. c Emission spectra of selected silicon-bridged heterocycles in $\mathrm{CHCl}_{3}\left(10^{-5} \mathrm{M}\right)$. d $\mathrm{CD}$ (circular dichroism) spectra of compound ( $R$ )-4d (purple line, $91 \%$ ee) and (S)-4d (green line, $88 \%$ ee) in $\mathrm{CHCl}_{3}\left(2.0 \times 10^{-4} \mathrm{M}\right.$ ) at room temperature. e $\mathrm{CPL}$ (circular polarized luminescence) spectra of compound ( $R$ )-4d (purple line, $91 \%$ ee) and (S)-4d (green line, $88 \%$ ee) in $\mathrm{CHCl}_{3}\left(2.0 \times 10^{-3} \mathrm{M}\right.$ ) at room temperature, excited at $339 \mathrm{~nm}$. $\mathbf{f} g_{\text {lum }}$ (Luminescence dissymmetry factor) values-wavelength curve for $(R)-\mathbf{4 d}$ (purple line, $91 \%$ ee) and $(S)$-4d (green line, $88 \%$ ee).

trifluoromethyl (2e), chloro (2f), fluoro (2g) groups, as well as naphthyl (2i) and thiophenyl (2j) groups in different positions, were all well tolerated in the transformation, affording the corresponding asymmetrically triorgano-substituted silicon-stereogenic indole based silanes in good to excellent yields and enantioselectivities. Then, the silyl group tethered aromatic rings ( $\mathrm{Ar}^{2}$, green part) were also investigated under the standard conditions. Naphthalene, morpholine, benzothiophene, benzofuran, thiophene, and alkyl chain $(\mathbf{2 k - 2 p )}$ were all compatible functionalities in the process, giving the desired products without the loss of enantioselectivities. For the indole based hetero-aromatic rings ( $\mathrm{Ar}^{3}$, blue part), we found that benzyl (2q) and phenyl (2r) substituted indoles were competent substrates in the reaction. Besides indole skeleton, benzofuran (2s), benzothiophene $(2 \mathbf{t}, 2 \mathbf{u})$, and naphthalene $(2 \mathbf{v}, 2 \mathbf{w})$ were also well accommodated in this transformation to deliver the interesting six-membered triorgano-substituted silicon-stereogenic heterocycles in moderate to good yields with excellent enantioselectivities. It is noteworthy that the enantiopure six-membered bissilicon-stereogenic heterocycles $(\mathbf{2 w})$ is easily constructed via this strategy, which could be highly attractive to organic material chemists, given that silicon-bridged ladder $\pi$-conjugated systems are an important class of useful skeletons in material sciences ${ }^{11-13}$. Finally, we found that the silicon-stereogenic phenazasiline (silicon-bridged diphenylamine) derivatives (2x), that usually exhibiting unique 
optical and electronic properties ${ }^{62,63}$, could also be synthesized by this rhodium-catalyzed dehydrogenative $\mathrm{C}-\mathrm{H}$ silylation, albeit in a relatively lower yield and $e e$.

Substrate scope of seven-membered triorgano-substituted silicon-stereogenic heterocycles. Moreover, the scope for this rhodium-catalyzed enantioselective $\mathrm{C}-\mathrm{H}$ silylation for the construction of seven-membered triorgano-substituted silicon-stereogenic heterocycles is explored. On the basis of the established reaction conditions, simply changing Josiphos ligand from L1 to L3 (see Supplementary Table 1 for details), several seven-membered carbazole-based silicon-stereogenic heterocycles displaying a variety of substituents were obtained in good yields and enantioselectivities (Fig. 4). Methoxy, OBn, OTs, phenyl, fluoro, and thiophenyl functional groups were all well tolerated in the transformation (4a-4e). These results demonstrate the facile enantioselective construction of silicon-stereogenic centers in medium-sized rings.

Synthetic applications. To further probe the synthetic utility of the enantioenriched six- and seven-membered silicon-stereogenic heterocycle products, several elaborate stereospecific transformations were performed (Fig. 5). Hydrosilylation of vinyl ether, or internal alkyne, or acetone with the enantioenriched sixmembered monohydrosilane compound $\mathbf{2 a}$ in the presence of the $\mathrm{Rh} /$ (racemic)-Josiphos L1 catalyst or $\mathrm{Pt}(\mathrm{dvds})$ ( $\mathrm{dvds}=1,1,3,3$ tetramethyl-1,3-divinyldisiloxane) catalyst gave the corresponding tetraorgano-substituted functionalized silane product $\mathbf{5 a}, \mathbf{5 b}$, 5d, respectively, without the loss of enantiopurity. Coupling of $\mathbf{2 a}$ with 4-iodoanisole in the presence of the $\operatorname{Pd}\left(t \mathrm{Bu}_{3} \mathrm{P}\right)_{2}$ catalyst afforded the arylation silane product $5 \mathrm{c}$ in $72 \%$ yield and excellent enantiomeric purity. Moreover, treatment of the enantioenriched seven-membered monohydrosilane compound $4 \mathbf{a}(90 \% e e)$ with 2 equivalent vinyl ferrocene produced the oxidative alkenylation product $\mathbf{6 a}$ in $50 \%$ yield and $90 \%$ ee.

Photophysical properties investigations. Having established the asymmetric construction of various six- and seven-membered chiral silicon-bridged heterocycle compounds, we finally examined the photophysical properties of selected products (Fig. 6). Apparently, most of these compounds display bright blue fluorescence under UV light irradiation $(365 \mathrm{~nm})$ (Fig. 6a). The absorption and emission maxima of these compounds alter from 333 to $382 \mathrm{~nm}$, and 378 to $417 \mathrm{~nm}$, respectively (Fig. 6b, c) (see Supplementary Table 2 for details). A remarkable red-shift was observed from $2 \mathbf{v}$ to $2 \mathbf{w}$ for both the absorption and emission maxima, due to the extended $\pi$-conjugated system. The sevenmembered silicon-bridged heterocycle with electron-donating OBn group exhibits blue-shift than the one with electronwithdrawing OTs group in absorption maxima (4b vs $\mathbf{4 c}$ ). Then, the chiroptical properties of the seven-membered silicon-bridged heterocycles $(R)$-4d and $(S)$-4d were investigated based on circular dichroism $(\mathrm{CD})$ and circular polarized luminescence (CPL) spectroscopies. The CD spectra of $(R)-\mathbf{4 d}$ and $(S)$-4d was a mirror image and displayed clear Cotton effects at around 317 and 372 $\mathrm{nm}$, respectively (Fig. 6d). The CPL maxima of $(R)-\mathbf{4 d}$ and $(S)-\mathbf{4 d}$ in $\mathrm{CHCl}_{3}$ solution were at 423 and $419 \mathrm{~nm}$ with the corresponding dissymmetry factors at emission maxima $\left(g_{\text {lum }}\right)$ being $4.7 \times 10^{-4}$ and $-3.2 \times 10^{-4}$, respectively (Fig. $6 e, \mathrm{f}$ ).

In summary, we have developed a rhodium-catalyzed enantioselective dehydrogenative $\mathrm{C}-\mathrm{H}$ silylation methodology, which enables the construction of a wide range of six- and sevenmembered triorgano-substituted silicon-stereogenic heterocycles in good to excellent yields and enantioselectivities. Most of these silicon-bridged heterocycles exhibit bright blue fluorescence. We believe that these previously inaccessible asymmetrically siliconstereogenic heterocycles will find widespread use among synthetic chemistry and optoelectronic materials science.

\section{Methods}

General Procedure for the enantioselective construction of six-membered silicon-stereogenic heterocycle $\mathbf{2 a}$. A $5 \mathrm{~mL}$ microwave tube was charged with 1a $(0.1 \mathrm{mmol}, 31.3 \mathrm{mg}),[\mathrm{Rh}(\mathrm{cod}) \mathrm{Cl}]_{2}(0.5 \mathrm{mg}, 1 \mathrm{~mol} \%), \mathrm{Ll}(1.6 \mathrm{mg}, 3 \mathrm{~mol} \%)$, and toluene $(1 \mathrm{~mL})$ in glovebox. The tube was sealed, then removed from the glovebox, and the mixture was stirred at $70^{\circ} \mathrm{C}$ for $6 \mathrm{~h}$. After the completion of the reaction, the solvent was evaporated under reduced pressure and the residue was purified by flash column chromatography on a silica gel to give $2 \mathbf{a}$ as a white solid ( $25.9 \mathrm{mg}$, $83 \%$ yield).

\section{Data availability}

The data that support the findings of this study are available within the paper and its supplementary information files. Raw data are available from the corresponding author on reasonable request. Materials and methods, experimental procedures, characterization data, ${ }^{1} \mathrm{H},{ }^{13} \mathrm{C},{ }^{19} \mathrm{~F}$ NMR spectra and mass spectrometry data are available in the Supplementary Information. The X-ray crystallographic coordinates for structures reported in this study have been deposited at the Cambridge Crystallographic Data Centre (CCDC), under deposition numbers CCDC 2031952 (2j), and CCDC 2031700 (6a). These data can be obtained free of charge from The Cambridge Crystallographic Data Centre via www.ccdc.cam.ac.uk/data_request/cif.

Received: 15 November 2020; Accepted: 25 January 2021; Published online: 23 February 2021

\section{References}

1. Dubac, J., Laporterie, A. \& Manuel, G. Group 14 metalloles. 1. Synthesis, organic chemistry, and physicochemical data. Chem. Rev. 90, 215-263 (1990).

2. Hissler, M., Dyer, P. W. \& Reau, R. Linear organic $\pi$-conjugated systems featuring the heavy Group 14 and 15 elements. Coord. Chem. Rev. 244, 1-44 (2003).

3. Chen, J. \& Cao, Y. Silole-containing polymers: chemistry and optoelectronic properties. Macromol. Rapid Commun. 28, 1714-1742 (2007).

4. Ohshita, J. Conjugated oligomers and polymers containing dithienosilole units. Macromol. Chem. Phys. 210, 1360-1370 (2009).

5. Wong, W. W. H., Hooper, J. F. \& Holmes, A. B. Silicon analogues of polyfluorene as materials for organic electronics. Aust. J. Chem. 62, 393-401 (2009).

6. Corey, J. Y. Siloles: part 2: silaindenes (benzosiloles) and silafluorenes (dibenzosiloles): synthesis, characterization, and applications. $A d v$. Organomet. Chem. 59, 181-328 (2011).

7. Fu, H. \& Cheng, Y. Electroluminescent and photovoltaic properties of silole based materials. Curr. Org. Chem. 16, 1423-1446 (2012).

8. Zhao, Z., He, B. \& Tang, B. Z. Aggregation-induced emission of siloles. Chem Sci. 6, 5347-5365 (2015).

9. Khabashesku, V. N., Balaji, V., Boganov, S. E., Nefedov, O. M. \& Michl, J. Matrix isolation of silacyclopentadienes: UV-visible and IR spectra and photochemical interconversion. J. Am. Chem. Soc. 116, 320-329 (1994).

10. Yamaguchi, S. \& Tamao, K. Silole-containing $\pi$-conjugated polymers. 5 . Theoretical study of the electronic structure of $2,2^{\prime}$-bisilole in comparison with 1,1'-bi-1,3-cyclopentadiene: $\sigma^{*}-\pi^{*}$ conjugation and a low-lying LUMO as the origin of the unusual optical properties of $3,3^{\prime}, 4,4^{\prime}$-tetraphenyl-2,2'-bisilole. Bull. Chem. Soc. Jpn. 69, 2327-2334 (1996).

11. Yamaguchi, S. \& Tamao, K. Silole-containing $\sigma$ - and $\pi$-conjugated compounds. J. Chem. Soc. Dalton Trans. 3693-3702 (1998).

12. Yamaguchi, S. \& Tamao, K. A key role of orbital interaction in the main group element-containing $\pi$-electron systems. Chem. Lett. 34, 2-7 (2005).

13. Shimizu, M. \& Hiyama, T. Silicon-bridged biaryls: molecular design, new synthesis, and luminescence control. Synlett 23, 973-989 (2012).

14. Cheng, C. \& Hartwig, J. F. Catalytic silylation of unactivated C-H bonds. Chem. Rev. 115, 8946-8975 (2015).

15. Dang Tuan, T. et al. Advances in synthesis of $\pi$-extended benzosilole derivatives and their analogs. Molecules 25, 548 (2020).

16. Richter, S. C. \& Oestreich, M. Emerging strategies for C-H silylation. Trends Chem. 2, 13-27 (2020).

17. Chen, R.-F., Fan, Q.-L., Zheng, C. \& Huang, W. A General strategy for the facile synthesis of 2,7-dibromo-9-heterofluorenes. Org. Lett. 8, 203-205 (2006).

18. Matsuda, T., Kadowaki, S., Goya, T. \& Murakami, M. Synthesis of silafluorenes by iridium-catalyzed $[2+2+2]$ cycloaddition of silicon-bridged diynes with alkynes. Org. Lett. 9, 133-136 (2007). 
19. Furukawa, S., Kobayashi, J. \& Kawashima, T. Development of a sila-FriedelCrafts reaction and its application to the synthesis of dibenzosilole derivatives. J. Am. Chem. Soc. 131, 14192-14193 (2009).

20. Tobisu, M., Onoe, M., Kita, Y. \& Chatani, N. Rhodium-catalyzed coupling of 2-silylphenylboronic acids with alkynes leading to benzosiloles: catalytic cleavage of the carbon-silicon bond in trialkylsilyl groups. J. Am. Chem. Soc. 131, 7506-7507 (2009).

21. Ureshino, T., Yoshida, T., Kuninobu, Y. \& Takai, K. Rhodium-catalyzed synthesis of silafluorene derivatives via cleavage of silicon-hydrogen and carbon-hydrogen bonds. J. Am. Chem. Soc. 132, 14324-14326 (2010)

22. Yabusaki, Y. et al. Versatile synthesis of blue luminescent siloles and germoles and hydrogen-bond-assisted color alteration. Chem. Eur. J. 16, 5581-5585 (2010).

23. Liang, Y., Zhang, S. \& Xi, Z. Palladium-catalyzed synthesis of benzosilolo[2,3b]indoles via cleavage of a $\mathrm{C}\left(\mathrm{sp}^{3}\right)-\mathrm{Si}$ bond and consequent intramolecular $\mathrm{C}$ $\left(\mathrm{sp}^{2}\right)$-Si coupling. J. Am. Chem. Soc. 133, 9204-9207 (2011).

24. Onoe, M. et al. Rhodium-catalyzed carbon-silicon bond activation for synthesis of benzosilole derivatives. J. Am. Chem. Soc. 134, 19477-19488 (2012).

25. Leifert, D. \& Studer, A. 9-Silafluorenes via base-promoted homolytic aromatic substitution (BHAS) - the electron as a catalyst. Org. Lett. 17, 386-389 (2015).

26. Murai, M., Matsumoto, K., Takeuchi, Y. \& Takai, K. Rhodium-catalyzed synthesis of benzosilolometallocenes via the dehydrogenative silylation of $\mathrm{C}$ $\left(\mathrm{sp}^{2}\right)-\mathrm{H}$ bonds. Org. Lett. 17, 3102-3105 (2015).

27. Shibata, T., Shizuno, T. \& Sasaki, T. Enantioselective synthesis of planar-chiral benzosiloloferrocenes by Rh-catalyzed intramolecular $\mathrm{C}-\mathrm{H}$ silylation. Chem. Commun. 51, 7802-7804 (2015).

28. Shintani, R., Kurata, H. \& Nozaki, K. Rhodium-catalyzed intramolecular alkynylsilylation of alkynes. Chem. Commun. 51, 11378-11381 (2015).

29. Zhang, Q.-W., An, K., Liu, L.-C., Yue, Y. \& He, W. Rhodium-catalyzed enantioselective intramolecular $\mathrm{C}-\mathrm{H}$ silylation for the syntheses of planarchiral metallocene siloles. Angew. Chem. Int. Ed. 54, 6918-6921 (2015).

30. Zhang, Q.-W. et al. Construction of chiral tetraorganosilicons by tandem desymmetrization of silacyclobutanes/intermolecular dehydrogenative silylation. Angew. Chem. Int. Ed. 56, 1125-1129 (2017).

31. Citron, J. D. Preparation, resolution, and dynamic stereochemistry of the $7 \mathrm{H}-$ 7-methyl-7-silabenz[d,e] anthracene system. J. Organomet. Chem. 86, 359-367 (1975).

32. Huang, C. \& Gevorgyan, V. TBDPS and Br-TBDPS protecting groups as efficient aryl group donors in Pd-catalyzed arylation of phenols and anilines. $J$. Am. Chem. Soc. 131, 10844-10845 (2009).

33. Nakashima, T. et al. Fluorescence and phosphorescence of a series of siliconcontaining six-membered-ring molecules. J. Organomet. Chem. 805, 27-33 (2016).

34. Misawa, N., Tsuda, T., Shintani, R., Yamashita, K. \& Nozaki, K. Palladiumcatalyzed intramolecular $\mathrm{C}-\mathrm{H}$ arylation versus 1,5 -palladium migration: a theoretical investigation. Chem. Asian J. 13, 2566-2572 (2018).

35. Zhao, W.-T., Lu, Z.-Q., Zheng, H., Xue, X.-S. \& Zhao, D. Rhodium-catalyzed 2-arylphenol-derived six-membered silacyclization: straightforward access toward dibenzooxasilines and silicon-containing planar chiral metallocenes. ACS Catal. 8, 7997-8005 (2018).

36. Qin, Y., Han, J.-L., Ju, C.-W. \& Zhao, D. Ring expansion to 6-, 7-, and 8membered benzosilacycles through strain-release silicon-based cross-coupling. Angew. Chem. Int. Ed. 59, 8481-8485 (2020)

37. Sasaki, I., Ohmura, T. \& Suginome, M. Construction of silicon-containing seven-membered rings by catalytic $[4+2+1]$ cycloaddition through rhodium silylenoid. Org. Lett. 22, 2961-2966 (2020).

38. Tsuda, T., Kawakami, Y., Choi, S.-M. \& Shintani, R. Palladium-catalyzed synthesis of benzophenanthrosilines by $\mathrm{C}-\mathrm{H} / \mathrm{C}-\mathrm{H}$ coupling through 1,4palladium migration/alkene stereoisomerization. Angew. Chem. Int. Ed. 59, 8057-8061 (2020).

39. Shintani, R., Moriya, K. \& Hayashi, T. Palladium-catalyzed enantioselective desymmetrization of silacyclobutanes: construction of silacycles possessing a tetraorganosilicon stereocenter. J. Am. Chem. Soc. 133, 16440-16443 (2011).

40. Shintani, R., Moriya, K. \& Hayashi, T. Palladium-catalyzed desymmetrization of silacyclobutanes with alkynes: enantioselective synthesis of siliconstereogenic 1-sila-2-cyclohexenes and mechanistic considerations. Org. Lett. 14, 2902-2905 (2012).

41. Shintani, R., Maciver, E. E., Tamakuni, F. \& Hayashi, T. Rhodium-catalyzed asymmetric synthesis of silicon-stereogenic dibenzooxasilines via enantioselective transmetalation. J. Am. Chem. Soc. 134, 16955-16958 (2012).

42. Sato, Y., Takagi, C., Shintani, R. \& Nozaki, K. Palladium-catalyzed asymmetric synthesis of silicon-stereogenic 5,10-dihydrophenazasilines via enantioselective 1,5-palladium migration. Angew. Chem. Int. Ed. 56, 9211-9216 (2017).

43. Chen, H. et al. Rhodium-catalyzed reaction of silacyclobutanes with unactivated alkynes to afford silacyclohexenes. Angew. Chem. Int. Ed. 58, 4695-4699 (2019).
44. Sommer, L. H., Michael, K. W. \& Fujimoto, H. Stereochemistry of asymmetric silicon. Stereospecific platinum-catalyzed hydrosilation of 1-octene with optically active $\mathrm{R}_{3} \mathrm{Si}^{*}$ H. J. Am. Chem. Soc. 89, 1519-1521 (1967).

45. Oestreich, M. \& Rendler, S. "True" chirality transfer from silicon to carbon: asymmetric amplification in a reagent-controlled palladium-catalyzed hydrosilylation. Angew. Chem. Int. Ed. 44, 1661-1664 (2005).

46. Rendler, S., Oestreich, M., Butts, C. P. \& Lloyd-Jones, G. C. Intermolecular chirality transfer from silicon to carbon: interrogation of the two-silicon cycle for Pd-catalyzed hydrosilylation by stereoisotopochemical crossover. J. Am. Chem. Soc. 129, 502-503 (2007).

47. Oestreich, M. Silicon-stereogenic silanes in asymmetric catalysis. Synlett 1629-1643 (2007)

48. Rendler, S., Froehlich, R., Keller, M. \& Oestreich, M. Enantio- and diastereotopos differentiation in the palladium(II)-catalyzed hydrosilylation of bicyclo[2.2.1]alkene scaffolds with silicon-stereogenic silanes. Eur. J. Org. Chem. 2582-2591 (2008).

49. Kawakami, Y. et al. Control of stereochemical structures of silicon-containing polymeric systems. Polym. Int. 58, 279-284 (2009).

50. Igawa, K. \& Tomooka, K. Chiral silicon molecules. In Organosilicon Chemistry: Novel Approaches and Reactions (eds. Hiyama, T. \& Oestreich, M.) 495-532 (Wiley, 2019).

51. Xu, L.-W., Li, L., Lai, G.-Q. \& Jiang, J.-X. The recent synthesis and application of silicon-stereogenic silanes: a renewed and significant challenge in asymmetric synthesis. Chem. Soc. Rev. 40, 1777-1790 (2011).

52. Weickgenannt, A. \& Oestreich, M. The renaissance of silicon-stereogenic silanes: a personal account. In Asymmetric Synthesis: More Methods and Applications (eds. Christmann, M. \& Bräse, S.) 35-42 (Wiley, 2012).

53. Bauer, J. O. \& Strohmann, C. Recent progress in asymmetric synthesis and application of difunctionalized silicon-stereogenic silanes. Eur. J. Inorg. Chem. 2016, 2868-2881 (2016)

54. Xu, L.-W. Desymmetrization catalyzed by transition-metal complexes: enantioselective formation of silicon-stereogenic silanes. Angew. Chem. Int. Ed. 51, 12932-12934 (2012).

55. Cui, Y.-M., Lin, Y. \& Xu, L.-W. Catalytic synthesis of chiral organoheteroatom compounds of silicon, phosphorus, and sulfur via asymmetric transition metal-catalyzed C-H functionalization. Coord. Chem. Rev. 330, 37-52 (2017).

56. Shintani, R. Recent progress in catalytic enantioselective desymmetrization of prochiral organosilanes for the synthesis of silicon-stereogenic compounds. Synlett 29, 388-396 (2018).

57. $\mathrm{Mu}, \mathrm{D}$. et al. Streamlined construction of silicon-stereogenic silanes by tandem enantioselective C-H silylation/alkene hydrosilylation. J. Am. Chem. Soc. 142, 13459-13468 (2020).

58. Yang, B., Yang, W., Guo, Y., You, L. \& He, C. Enantioselective silylation of aliphatic $\mathrm{C}-\mathrm{H}$ bonds for the synthesis of silicon-stereogenic dihydrobenzosiloles. Angew. Chem. Int. Ed. 59, 22217-22222 (2020).

59. Boudjouk, P., Rajkumar, A. B. \& Parker, W. L. Nickel-catalyzed coupling of phenylhydrosilanes. J. Chem. Soc. Chem. Commun. 245-246 (1991).

60. Rosenberg, L., Davis, C. W. \& Yao, J. Catalytic dehydrogenative coupling of secondary silanes using Wilkinson's catalyst. J. Am. Chem. Soc. 123, 5120-5121 (2001).

61. Shimizu, M., Mochida, K. \& Hiyama, T. Modular approach to silicon-bridged biaryls: palladium-catalyzed intramolecular coupling of 2-(arylsilyl)aryl triflates. Angew. Chem. Int. Ed. 47, 9760-9764 (2008).

62. Nakao, H., Hayashi, H. \& Okita, K. Spectroelectrochemical characterization of Si-bridged diphenylamines: influence of Si-bridging upon electronic structures of diphenylamines. Anal. Sci. 17, 545-549 (2001).

63. Li, H. et al. Efficient synthesis of $\pi$-extended phenazasilines for optical and electronic applications. Chem. Commun. 50, 15760-15763 (2014).

\section{Acknowledgements}

We are grateful for financial support from the National Natural Science Foundation of China (21901104), the Thousand Talents Program for Young Scholars, the startup fund from Southern University of Science and Technology, and Guangdong Provincial Key Laboratory of Catalysis (No. 2020B121201002). We also thank Prof Feng He (SUSTech), Prof. Wei Lu (SUSTech), Dr. Tingxing Zhao (SUSTech), and Dr. Chao Zou (SUSTech) for their kind help with the photophysical properties investigations.

\section{Author contributions}

S.C., D.M., P.M., and J.K. developed and conducted the reactions. Y.L. conducted the DFT calculations. C.H. designed and directed the investigations and wrote the paper. All correspondence should be sent to C.H. (hec@sustech.edu.cn).

\section{Competing interests}

The authors declare no competing interests. 


\section{Additional information}

Supplementary information The online version contains supplementary material available at https://doi.org/10.1038/s41467-021-21489-6.

Correspondence and requests for materials should be addressed to C.H.

Peer review information Nature Communications thanks the anonymous reviewer(s) for their contribution to the peer review of this work.

Reprints and permission information is available at http://www.nature.com/reprints

Publisher's note Springer Nature remains neutral with regard to jurisdictional claims in published maps and institutional affiliations. (c) (1) Open Access This article is licensed under a Creative Commons Attribution 4.0 International License, which permits use, sharing, adaptation, distribution and reproduction in any medium or format, as long as you give appropriate credit to the original author(s) and the source, provide a link to the Creative Commons license, and indicate if changes were made. The images or other third party material in this article are included in the article's Creative Commons license, unless indicated otherwise in a credit line to the material. If material is not included in the article's Creative Commons license and your intended use is not permitted by statutory regulation or exceeds the permitted use, you will need to obtain permission directly from the copyright holder. To view a copy of this license, visit http://creativecommons.org/ licenses/by/4.0/.

(C) The Author(s) 2021 